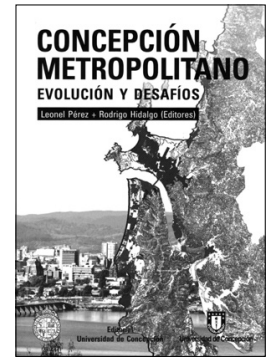

\title{
Leonel Pérez y Rodrigo Hidalgo (eds.). Concepción metropolitano: evolución y desafíos
}

\author{
Concepción: Editorial Universidad de Concepción, \\ Instituto de Geografía, Pontificia Universidad Católica \\ de Chile, Serie GEOlibros 14, 2010. 318 p.
}

\author{
Paula Villagra Islas ${ }^{1}$
}

El libro Concepción Metropolitano: evolución y desafíos, es una aproximación multiescalar, interdisciplinar y longitudinal, amplia y transversal, a las problemáticas y potencialidades del Área Metropolitana de Concepción (AMC). En el texto se plantean diversas temáticas que influyen en el desarrollo del AMC, desde el emplazamiento de la ciudad de Concepción en el valle de la Mocha hasta su desarrollo en el área metropolitana que es hoy, incluyendo comunas emplazadas en un contexto geográfico singular. Un total de diez comunas configuran el AMC, y se distribuyen en un territorio caracterizado por las bahías de Coronel, San Vicente y Concepción, por el ancho del río Biobío y por los cordones de la cordillera de Nahuelbuta, que limitan el crecimiento urbano hacia el interior.

El libro se publica en un momento clave para la planificación urbana y territorial de Chile, luego del terremoto del 27 de febrero de 2010, tras el cual se debe reconstruir una gran área del territorio nacional. En el ámbito de la reconstrucción de ciudades postdesastre se plantea que para lograr una reconstrucción exitosa y de largo plazo se deben considerar las diversas dimensiones que envuelven la estructura y el funcionamiento de una ciudad (Vale \& Campanella, 2005). Estas incluyen la dimensión territorial, urbana, natural, social y temporal, entre otras, y el libro Concepción

\footnotetext{
1 Ph. D., Arquitecta y arquitecta del paisaje. Académica Instituto de Arquitectura y Urbanismo, Universidad Austral de Chile (Chile).E-mail: paula_villagra@ yahoo.com
}

Metropolitano: evolución y desafíos, plantea oportunamente, por medio de la investigación y discusión de ingenieros forestales, geógrafos, arquitectos, historiadores, economistas y biólogos, diversas temáticas asociadas a estas dimensiones en el contexto de la planificación urbana y territorial local.

El libro se estructura en tres partes, cada una integrada por varios artículos de investigaciones finalizadas o en curso. En la primera parte titulada Evolución urbana y planes metropolitanos, se explican las dinámicas territoriales, políticas y sociales, cómo se han sucedido y afectado el desarrollo del AMC. La lectura conjunta de los artículos de esta parte del libro pone en evidencia la falta de una planificación territorial y urbana integradora que abarque las dimensiones sociales, económicas y ambientales, con visión a futuro, y que considere las arquitecturas, espacios abiertos y elementos naturales como valores a rescatar e interrelacionar. Se discute acertadamente, y como una de las principales problemáticas, la preexistencia de un conjunto de planes reguladores muy permisivos, que no controlaron el crecimiento urbano a tiempo y tampoco respondieron a la diversidad social, expresiones comunitarias distintas y a la necesidad de articulación espacial entre los asentamientos.

La lectura que ofrece la segunda parte del libro denominada Procesos socioespaciales y dinámicas metropolitanas, se enfoca en la dimensión social al plantear los problemas que ha traído al AMC la inadecuada localización y distribución de infraestructura, ya sea de 
vivienda, transporte e industria, y su efecto en la segregación espacial y fragmentación urbana. Los autores plantean que dentro de las variables que se han descuidado están la ubicación y cantidad de viviendas sociales, y la falta de políticas adecuadas que regulen esta situación. La consolidación de recientes proyectos inmobiliarios también se subraya como una de las causas de la evidente y continuada segregación residencial y social. Estos proyectos se distribuyen preferentemente en entornos naturales valorados y exclusivos, de buena accesibilidad y con mayor cantidad de áreas verdes, lo que ha generado núcleos urbanos aislados y, en consecuencia, un crecimiento urbano tentacular $y$ fragmentado que ha eliminado elementos y sistemas naturales, omitiendo el factor riesgo en la planificación urbana. En este contexto se plantea muy acertadamente la necesidad de mirar la ciudad desde la perspectiva de la movilidad y situar el rol del transporte público dentro de una ciudad fragmentada social y espacialmente, además de reorientar el consumo del suelo, hoy poco eficiente debido a la continua expansión urbana.

La ineludible mirada más amplia del territorio se desarrolla en la tercera y última parte del libro titulada Proyectos, fragmentos urbanos y la sustentabilidad del crecimiento metropolitano. En esta parte la ciudad se investiga y discute desde la dimensión territorial y dinámica, considerando el crecimiento y desarrollo del AMC en relación a su entorno natural. El crecimiento urbano disperso que ha tenido el AMC ha fragmentado ambientes ecológicos lo que ha traído consecuencias socioeconómicas, afectando principalmente a los grupos sociales más pobres. Esta misma manera fragmentada de crecer, típica de muchas otras áreas metropolitanas, se describe como la causa de proliferación de vacíos metropolitanos, imprecisos y sin urbanidad, pero los que a su vez se visualizan y proponen como la base para un proyecto de ciudad a escala territorial. Por otro lado, la falta de consideración en la planificación urbana del río y del paisaje fluvial dinámico que este caracteriza, ha dejado a libre albedrío la interpretación que hace el habitante de la cuenca del río $y$, por consecuencia, la manera en que la interviene. Por ejemplo, y basados en el modo de crecimiento de la ciudad de Concepción desde su fundación, se describen una serie de paisajes culturales que han más bien negado que incorporado el ambiente fluvial durante la historia de la ciudad. Ahondar empíricamente en este tipo de interpretaciones es altamente relevante, ya que el mismo río crea un paisaje fluvial que modifica los sistemas hídricos y el medio ambiente (clima, reservorios de agua, hábitat, entre otros) y, como bien se plantea, la falta de planificación de su cuenca genera espacios inadecuados para soportar eventos extremos, aumentando la superficie de peligrosidad y riesgo en la ciudad.

De la lectura cruzada de los artículos se esbozan otras temáticas que permiten ahondar y enriquecer la exploración de las dimensiones que influyen en el desarrollo de un área metropolitana. Aparte de los tres grandes temas planteados en las distintas partes del libro, existen otros que subyacen a ellos y que los autores plantean en forma reiterativa, compartiendo similares posturas.

Uno de los temas emergentes es la ansiada relación entre el desarrollo urbano, la calidad de vida y los ambientes naturales, lo cual no se observa a nivel de planificación urbana normalmente en Chile. Existen aspectos sicológicos e individuales de una persona que se mejoran al mantener el contacto con el entorno natural, pero no con cualquier entorno (Aragonés y Amérigo, 2002). Un medio ambiente fragmentado, enfermo y amenazante, puede ser el resultado de una planificación no adecuada, lo cual genera ambientes que normalmente no son bien recibidos por un individuo o una comunidad. La ciudad de Concepción, como se plantea en el texto, desde su historia se ha desarroIlado en contraste a las formas y dinámicas de los ríos que la envuelven (Biobío y Andalién), modificando, construyendo y transgrediendo sus cuencas y humedales asociados, lo que da como resultado paisajes riesgosos. Las consecuencias de estas intervenciones no son menores ya que un paisaje amenazante y que disminuye la calidad de vida, no es valorado, ni amado, lo que usualmente conlleva al descuido y final destrucción del medio. Por esta razón, reconocer e incluir la dimensión perceptual del paisaje urbano no es menor al momento de la planificación urbana y la reconstrucción de ciudades, ya 
que esta es determinante en el comportamiento y bienestar de las personas (Vale \& Campanella, 2005).

Dentro de esta línea, existe otro aspecto que emerge de la lectura. Es la necesidad de desarrollar investigación aplicada para conocer las características del paisaje urbano. En la tercera parte del libro se comenta sobre este concepto y se describe como una consecuencia de la actividad humana sobre un territorio, lo cual afecta por un lado la realidad física y cultural. Se plantea como un recurso para activar la vida colectiva, lo cual no es menor si se piensa en la fragmentación espacial y social que caracteriza el AMC y muchas otras áreas metropolitanas de Chile. El paisaje es una voz abstracta e intuitiva de un observador basada en señales ambientales que posibilitan entender un lugar o territorio. El paisaje urbano, en particular, está compuesto por aspectos físicos y por significados, los cuales son el reflejo en conjunto de condiciones geográficas, arquitectónicas y socioculturales, Ilenos de resonancia, con idiomas propios que trazan el carácter de la ciudad y del habitante (Roca, 1984). Considerando la relevancia que tiene el paisaje urbano para la ciudad, se debiera profundizar en el estudio de sus características y significados, explorando además como integrarlo a la planificación y diseño urbano.

La integración de las diversas dimensiones, incluyendo la dimensión perceptual, en la planificación urbana y territorial es una realidad compleja pero ineludible, y como bien dicen los editores del libro "el actual paisaje urbano de Concepción y su área metropolitana son en gran parte resultado de los frecuentes terremotos que la han afectado... los encargados de la reconstrucción debieran tener presente en todo momento que no se están solucionando solamente los problemas del presente" (Pérez e Hidalgo, 2010: 14). Hoy existen estudios que explican las características del paisaje, como se categoriza, caracteriza y percibe, pero su aplicabilidad en el contexto urbano es aun un tema pendiente. Sobre todo, en territorios accidentados y cambiantes como lo es el chileno, constantemente afectado por disturbios tanto naturales como humanos, que modifican el paisaje de nuestras ciudades $y$, por consecuencia a sus habitantes.
Es más, el rol que juega el paisaje urbano en la capacidad de resiliencia de una ciudad ha sido un tema reciente de estudio en contextos norteamericanos y asiáticos (por ejemplo Allan \& Bryant, 2010). Sin embargo, ha sido escasamente profundizado en Chile. Varios de los autores de este libro no se equivocan en plantear que las funciones de una ciudad no solo incluyen otorgar el transporte, vivienda y equipamiento a la población, sino también las de proveer una buena calidad de vida, sostener una cultura y una sociedad con una identidad propia, por lo que valores que la ciudadanía le asigna al paisaje urbano debieran ser considerados en conjunto con los ecológicos, arquitectónicos y económicos en la planificación y gestión del territorio.

Se puede concluir que mediante la lectura cruzada de los artículos de este texto se manifiestan los desafíos interdisciplinarios en el ámbito del quehacer regional, no antes englobados, sintetizados y valorados de esta forma para su utilidad en la planificación territorial y urbana. Hay un énfasis particular en destacar temas que han estado pendientes por resolver desde la fundación de la ciudad de Concepción, como son el control de la segregación espacial y social, y la planificación territorial, integrando los sistemas naturales que sustentan el AMC. Además hay temáticas emergentes que se debieran anticipar e incluir en la planificación del territorio como situaciones ambientales, sociales y catastróficas, sobre todo después de los eventos telúricos, tsunámicos y sociales del 27 de febrero de 2010 .

En definitiva, el texto recopila, reorganiza, ofrece y sugiere un amplio material para poner a disposición de la planificación urbana del AMC y particularmente de la reconstrucción de la región. Propone una manera académica, pero a la vez sencilla y comprensible por el ciudadano común, de interrelacionar las diversas dimensiones que influyen en el desarrollo urbano, tema tanto de planificadores como de los habitantes. Se puede también leer como una propuesta metodológica para ser replicable en otras áreas metropolitanas existentes o emergentes de nuestro país con el objetivo de comprender sus problemáticas a tiempo. En el fondo, el libro busca contribuir en lo que los mismos editores llaman "un modelo de territorio metropolitano, que 
excede sus límites actuales" (Pérez e Hidalgo, 2010: 14) que incorpora dimensiones territoriales, urbanas y económicas, entre otras, pero también naturales, temporales y socioculturales.

\section{Referencias bibliográficas}

ALLAN, P. \& BRYANT, M. The critical role of open space in earthquake recovery: a case study. Wellington: New Zealand Society of Earthquake Engineering Conference, 2010.
ARAGONÉS, J. I. y AMÉRIGO, M. (eds.). Psicología ambiental. Madrid: Psicología Pirámide, 2002.

ROCA, M. A. Lugares urbanos y estrategias. Córdoba: Facultad de Arquitectura y Urbanismo, Universidad Nacional de Córdoba, 1984.

VALE, L. J. \& CAMPANELLA, T. J. (eds.). The resilient city, how modern cities recover from disaster. New York: Oxford University Press, 2005. 